Journal of Research in Interprofessional

Practice and

Education

Vol. 8.1

2018
Journal of Research in Interprofessional Practice and Education (JRIPE)

Vol. 8.1

(C) 2018

doi: 10.22230/jipe.2018 v8n1a264

Corresponding author: Shelley C. Mishoe. Email: smishoe@odu.edu

\section{Health Professions Students' Attitudes Toward Teamwork Before and After an Interprofessional Education Co-Curricular Experience}

\author{
Shelley C. Mishoe, PhD, FAARC, FASAHP; \\ Kimberly Adams Tufts, ND, FAAN; Leigh Ann Diggs, PhD; \\ James D. Blando, PhD; Denise M. Claiborne, PhD; \\ Johanna M. Hoch, PhD; Martha L. Walker, PhD \\ Old Dominion University
}

\begin{abstract}
Background: Effective interprofessional collaboration may positively impact clinical outcomes, patient satisfaction, and cost effectiveness. However, educational silos and discipline-specific socialization have reinforced each health profession's independent values, attitudes, and problem-solving approaches.

Methods and Findings: Students' $(N=376)$ attitudes about teamwork were measured with the Interprofessional Attitudes Scale, Teamwork, Roles, and Responsibilities subscale using a pretest-posttest design. Experiential learning strategies and a case study approach were used to introduce students to the roles and responsibilities of the students' disciplines. There was a positive mean difference in pretest-posttest measures $(p<.001)$ with a moderate effect size $(r=.27)$.

Conclusions: Providing opportunities for pre-licensure health sciences students to understand the roles and responsibilities of other disciplines through IPE co-curricular learning can enhance positive attitudes toward teamwork.

Keywords: Health sciences students; Interprofessional education; Teamwork; Roles and responsibilities; Co-curricular learning
\end{abstract}

\section{Introduction}

The importance of interprofessional teamwork has been recognized for more than four decades, but has only become a priority for education and practice in healthcare in recent years [1]. Educational traditions and specialization have prevented substantial progress in preparing health professionals with the attitudes and competencies needed for team-based care. Additional reports on safety [2], quality [3], interprofessional education (IPE) [4], and health outcomes [5] further emphasize the growing need for teamwork and interprofessional collaborative practice (IPCP). Work on interprofessional education and practice has occurred not only in the U.S., as proposed by the Institutes of Medicine (IOM), but also in Australia, Canada, Europe, New Zealand, the United Kingdom, and other countries with increasing global focus [6-11]. There is evidence that effective interprofessional healthcare teams may positively impact clinical outcomes [12-14], increase patient safety [15-17], reduce medical errors [18,19], improve patient satisfaction [20], and achieve cost effectiveness 
2

Students' Teamwork Before and After IPE

Mishoe, Tufts, Diggs, Blando, Claiborne, Hoch, \& Walker

Journal of Research in Interprofessional Practice and Education

Vol. 8.1

2018
[21-24]. Effective interprofessional teamwork in healthcare has also been associated with several positive employee outcomes, such as increased job satisfaction $[25,26]$, lower stress [27], and higher staff retention [26,28-30].

Educational silos and discipline-specific socialization, as well as social, gender, and hierarchal issues, have reinforced the independent values, attitudes, language, and problem-solving approaches of each health profession, which presents many challenges to effective interprofessional teamwork [31-33]. Healthcare systems have traditionally valued expert status with the independent practice of health professionals, resulting in a culture wherein individual, rather than collective, competence has prevailed. Thus, health professionals have been ill-prepared for collaboration and often compete instead of collaborate. Deficits in healthcare quality are often due to inadequate collaboration among members of interprofessional healthcare teams, along with gaps in constructive relationships among patients and providers [34]. To effectively engage in interprofessional collaborative practice that includes patients and their families, healthcare professionals must be familiar with the expertise, roles, and responsibilities of various professionals and value shared decision-making through authentic team-based care $[29,35,36]$. They must value interprofessional practice and be skilled in effective interprofessional communication [35].

To address the need for preparing health professionals with core competencies for IPCP, the dean of the College of Health Sciences (COHS) at a research-intensive public university formed an IPE taskforce to develop a college-wide proposal for creating an IPE and collaborative practice culture post-graduation [35]. The IPE task force recommendations were implemented within one academic year and included the creation of a new administrative position, the assistant dean for IPE, and additional budget for staff support, space, faculty professional development, student support, co-curricular learning, course development, and non-personnel expenses. A standing committee with representation from each of the five schools in the college, as well as student, community, and patient representatives, was formed to work with the assistant dean for IPE to establish a process for designing, developing, and implementing IPE in the college [10,37]. Initial work included a survey of curricula across the schools to identify courses that could support IPE, and the creation of additional curricular and co-curricular IPE learning experiences. This article reports on the findings from a co-curricular learning experience designed to engage students from different health professions in interactive learning about each other's professional roles and responsibilities in order to enhance the students' attitudes toward teamwork and interprofessional collaborative practice. The specific aims of this study were achieved; there was a significant increase in measures of teamwork following an IPE learning experience.

\section{Methods}

\section{Design}

A pretest-posttest design was used to assess student attitudes about teamwork before and after participation in the interprofessional co-curricular learning experience. The null hypothesis was that there were "no differences in students' attitudes 
3

Students' Teamwork Before and After IPE

Mishoe, Tufts, Diggs, Blando, Claiborne, Hoch, \& Walker
Journal of Research in Interprofessional Practice and Education

Vol. 8.1

2018 about teamwork from participation in an IPE co-curricular experience." The university's Institutional Review Board approved all study-related procedures.

\section{Sample}

A sample of students $(N=376)$ from the five schools of the College of Health Sciences, Community and Environmental Health, Dental Hygiene, Medical Diagnostics and Translational Sciences, Nursing, and Physical Therapy and Athletic Training, participated in this study.

\section{Procedures}

An interprofessional approach was used to expose students from various health disciplines to the scope of their own professional role and responsibilities as well as to those of others. Faculty used experiential learning strategies and a case study approach to introduce students to the principles inherent in the Interprofessional Education Collaborative's (IPEC) role and responsibilities competency. The purpose of the experience was to create a learning environment where students could learn about, with, and from each other in an environment devoid of the traditional educational silos that often inhibit interaction and collaboration among health professional students. The learning experience was part of a process within the college to facilitate the students' achievement of the four IPEC competencies through curricular and co-curricular strategies [35]. Upon registering, students were randomly assigned to interprofessional groups and to five different session schedules. Students remained in these groups across a four-hour period: the introductory session, the experiential learning sessions, and the debriefing session.

All students participated in a 30-minute kick-off session in which the principles of IPE were introduced, the IPEC competencies were reviewed, the sequence of activities was detailed, and the purpose of the learning opportunity was emphasized. During this session, students were asked to consider the case of a woman recently diagnosed with bladder cancer and undergoing chemotherapy treatment. The case was planned so that each discipline could use a learning session to present information or activities related to how their various professions addressed the concerns of the same patient: through laboratory analysis and diagnostics, direct patient care following diagnosis, screening for cancer-associated oral health problems, rehabilitation post chemotherapy, or the impact of environmental factors on the epidemiology of cancers (see Appendix A).

Students then travelled in their assigned interprofessional groups to each of the five schools in the COHS, where they participated in sessions that highlighted the disciplinary roles of various professions in relation to the case study. Five sessions took place, with students moving in groups to a different session every 30 minutes. Students were able to learn about, with, and from each other through the sessions and the case study, which focused on roles, responsibilities, and teamwork.

Students and faculty from each of the five schools of the COHS, who were trained by college IPE staff prior to the event, led these sessions. Faculty facilitators, except for the community member and some of those who assisted with the demonstrations, had also attended at least one of IPEC's professional development institutes. 
4

Students' Teamwork Before and After IPE

Mishoe, Tufts, Diggs, Blando, Claiborne, Hoch, \& Walker
Journal of Research in Interprofessional Practice and Education

Vol. 8.1

2018
The teaching-learning approach varied across the five schools, addressing professional roles and responsibilities for the particular case study. Faculty from the School of Community and Environmental Health utilized a lecture to teach students about the environmental risks that industrial hazards may pose to health and the role of industrial hygienists and environmental health professionals. In the School of Dental Hygiene, participants visited the Dental Hygiene Clinic, where students demonstrated how dental hygienists approach oral care and led a discussion about the impact of chemotherapy on oral health. The School of Medical Diagnostics and Translation Sciences used a lecture to highlight the role of cytotechnologists in diagnosing bladder cancer and gave an interactive demonstration with teaching microscopes, which accommodated multiple learners to visualize the differences between normal and abnormal bladder cells. Nursing faculty and students used a simulation approach to illustrate the nurse's role in coordinating different aspects of healthcare and the tenets of patient advocacy. Athletic training and physical therapy students taught participants about the differences and commonalities of their respective roles via lecture, demonstrations, and an experiential balance assessment and rehabilitation exercise. Each session allotted time for questions, answers, and interaction.

A scavenger hunt that highlighted each discipline's role took place as part of the educational experience. This technique was designed to keep participants engaged, underscore that learning is fun, and set the stage for the debriefing session. During travel time and in each session, the faculty facilitators encouraged continued interaction about the various professional roles grounded within the case study. All student participants then returned to a common room where debriefing took place in the form of a "student mixer." Students were encouraged to reflect on their experience. This was followed by a discussion of what was learned through the various experiential sessions. Prizes were awarded for the scavenger hunt activity. The posttest took place after the completion of the debriefing sessions.

\section{Measures}

\section{Demographic data}

All students were asked to complete a demographic form. The information collected in this document included basic demographic information, such as program type, educational level, preliminary knowledge about the term IPE, and the number of IPE events students had previously participated in.

\section{Teamwork, roles, and responsibilities subscale}

The Interprofessional Attitudes Scale (IPAS) was developed as an outcome measure to assess all four IPEC competencies. The IPAS is a 27-item scale with five separate subscales: Teamwork, Roles, and Responsibilities (TRR), Patient-Centeredness, Interprofessional Biases, Diversity and Ethics, and Community-Centeredness. For the purposes of this study, only the TRR portion of the IPAS was used. The TRR is comprised of nine items scored on a five-point Likert scale, from strongly disagree to strongly agree. The TRR questions are shown with the results. The TRR has demonstrated validity and internal consistency $(\alpha=0.91)$ [38]. 
5

Students' Teamwork Before and After IPE

Mishoe, Tufts, Diggs, Blando, Claiborne, Hoch, \& Walker
Journal of Research in Interprofessional Practice and Education

Vol. 8.1

2018

\section{Data management}

All survey data were assigned anonymous unique identifiers created by individual students. All data were checked for any personal identifiers and then de-identified. Paper questionnaires were kept in locked file cabinets in the IPE office of the COHS. Data from these questions were entered into the password-protected electronic database. The dependent variables were total scores on the TRR at pretest and posttest, and scores on each individual item. The independent variables were educational level (undergraduate or graduate), discipline (physical therapy, nursing, dental hygiene, or other), and number of prior IPE experiences (none, one to two experiences, or more than two).

\section{Data analyses}

Alpha was set a priori for all analyses, $p<.05$. All statistical analyses were performed in the Statistical Package for the Social Sciences (SPSS). Descriptive statistics were used to describe the sample. Frequencies (number and percentage) were used to describe the undergraduate and graduate students, the students by discipline, and any prior IPE participation. Cronbach's alpha was used to determine internal consistency for both the TRR pretest and posttest. Non-parametric inferential statistics were used to assess mean differences within subjects in the pretest and posttest scores on the TRR. The Wilcoxon Rank-Sum Test was also performed to discover differences in the total teamwork scores by student discipline, number of prior IPE experiences, and student educational level.

The Mann-Whitney U Test was used on the pretest and the posttest scores to determine if there were any significant differences between subjects based on a student's level of study or prior IPE experience. The Kruskal-Wallis Test was used to discover any pretest and/or posttest differences in students' perception of teamwork based on their discipline or their prior IPE experience. Post hoc analyses were performed using the Mann-Whitney $\mathrm{U}$ with Bonferroni correction.

\section{Results}

There were 376 student participants. Students were enrolled in physical therapy $(39.4 \%)$, dental hygiene (31.1\%), nursing $(21.3 \%)$, and other dsciplines $(8.2 \%)$ including nuclear medicine, cytotechnology, athletic training, medical technology, and environmental health programs. The majority of students had not previously participated in an IPE-learning activity (see Table 1).

The internal consistency of the TRR at pretest was acceptable $(\alpha=.65)$ and at posttest was good $(\alpha=.81)$. There was a mean difference in pretest and posttest
Table 1. Characteristics of student survey respondents

\begin{tabular}{|l|l|}
\hline Characteristics & $N(\%)$ \\
\hline Student level & \\
Undergraduate & $220(58.5 \%)$ \\
Graduate & $156(41.5 \%)$ \\
\hline Discipline & \\
Physical therapy & $148(39.4 \%)$ \\
Dental hygiene & $117(31.1 \%)$ \\
Nursing & $80(21.3 \%)$ \\
Other & $31(8.2 \%)$ \\
\hline Prior participation in IPE experiences & \\
None & $255(67.8 \%)$ \\
$1-2$ & $103(27.4 \%)$ \\
$>2$ & $18(4.8 \%)$ \\
\hline
\end{tabular}


TRR scores $(p<.001)$, with significant differences found for each item and for the

Students' Teamwork Before and After IPE

Mishoe, Tufts, Diggs, Blando, Claiborne, Hoch, \& Walker overall score with a moderate effect size $(r=.27)$ (see Table 2$)$. Further analyses showed significant differences in pretest and posttest scores for undergraduate students $(p<.001)$ and graduate students $(p<.001)$, and if the student had participated in one to two prior IPE experiences $(p<.05)$ or had no prior IPE experience $(p<$ .001) (see Table 3). There were no significant differences between pretest and posttest scores (see Table 3 ) for students who had two or more prior IPE experiences $(p=.082)$. There was a significant difference $(p<.001)$ between pretest and posttest means, regardless if students were in the discipline of nursing, physical therapy, or dental hygiene (see Table 3). Due to the small sample sizes, statistical analyses were not performed for the additional disciplines.

Table 2. Wilcoxon Rank Sum Test for pretest and posttest data comparison $(\boldsymbol{N}=376)$

\begin{tabular}{|l|c|c|c|c|c|c|}
\hline Question & $\begin{array}{c}\text { Pre median } \\
{[I Q R]}\end{array}$ & $\begin{array}{c}\text { Post median } \\
{[I Q R]}\end{array}$ & $\begin{array}{c}\text { Negative } \\
\text { mean rank }\end{array}$ & $\begin{array}{c}\text { Positive } \\
\text { mean rank }\end{array}$ & $Z^{*}$ & $\begin{array}{c}\text { Asymp.sig. } \\
(2 \text {-tailed) } p \text {-value })^{* *}\end{array}$ \\
\hline $\begin{array}{l}\text { 1. Shared learning before graduation will help me become a } \\
\text { better team worker. }\end{array}$ & $4[4,5]$ & $5[4,5]$ & 50.79 & 46.33 & $-6.322^{\mathrm{a}}$ & $<.001$ \\
\hline $\begin{array}{l}\text { 2. Shared learning will help me think positively about other } \\
\text { professionals. }\end{array}$ & $4[4,5]$ & $5[4,5]$ & 58.53 & 47.26 & $-6.016^{\mathrm{a}}$ & $<.001$ \\
\hline $\begin{array}{l}\text { 3. Learning with other students will help me become a more } \\
\text { effective member of the healthcare team. }\end{array}$ & $4[4,5]$ & $5[4,5]$ & 49.63 & 44.77 & $-4.159^{\mathrm{a}}$ & $<.001$ \\
\hline $\begin{array}{l}\text { 4. Shared learning with other health sciences students will } \\
\text { increase my ability to understand clinical problems. }\end{array}$ & $4[4,5]$ & $5[4,5]$ & 48.61 & 42.34 & $-3.763^{\mathrm{a}}$ & $<.001$ \\
\hline $\begin{array}{l}\text { 5. Patients will ultimately benefit if health sciences students } \\
\text { work together to solve patient problems. }\end{array}$ & $4[4,5]$ & $5[4,5]$ & 49.21 & 45.78 & $-2.429^{\mathrm{a}}$ & $<.05$ \\
\hline $\begin{array}{l}\text { 6. Shared learning with other health sciences students will help } \\
\text { me communicate better with patients and other professionals. }\end{array}$ & $4[4,5]$ & $5[4,5]$ & 48.75 & 45.01 & $-4.085^{\mathrm{a}}$ & $<.001$ \\
\hline $\begin{array}{l}\text { 7. I would welcome the opportunity to work on small-group } \\
\text { projects with other health sciences students. }\end{array}$ & $4[3,4]$ & $4[4,5]$ & 73.97 & 70.20 & $-6.101^{\mathrm{a}}$ & $<.001$ \\
\hline $\begin{array}{l}\text { 8. It is not necessary for health sciences students to learn } \\
\text { together. }\end{array}$ & $2[1,2]$ & $2[1,2]$ & 62.63 & 91.92 & $-2.394^{\mathrm{b}}$ & $<.05$ \\
\hline $\begin{array}{l}\text { 9. Shared learning will help me understand my own limita- } \\
\text { tions. }\end{array}$ & $4[4,4]$ & $4[4,5]$ & 62.48 & 58.74 & $-5.925^{\mathrm{a}}$ & $<.001$ \\
\hline \begin{tabular}{l} 
Teamwork Scale Total \\
\hline
\end{tabular} & $35[33,40]$ & $38[34,41]$ & 92.34 & 136.27 & $-7.462^{\mathrm{a}}$ & $<.001$ \\
\hline
\end{tabular}

Notes: ${ }^{\text {a }}$ based on negative ranks (pretest < posttest); ${ }^{b}$ based on positive ranks (posttest $>$ pretest); ${ }^{*} z$ is the number of standard deviations from the mean; ${ }^{* *}$ asymp. sig. is the asymptotic significance or $p$-value

Journal of Research in Interprofessional Practice and Education

Vol. 8.1

2018
The Mann-Whitney $U$ Test showed significant differences in the teamwork total scores of undergraduate students (mean rank $=215.06$ ) compared to graduate students pretest (mean rank 151.04, $U=11317.00, Z=-5.65, p<.001, r=.29$ ) and undergraduate students (mean rank $=192.72$ ) compared to graduate students' posttest (mean rank $=127.75, U=8073.00, Z=-6.12, p<.001, r=.32$. The Kruskal-Wallis tests also revealed differences based on students' discipline in the pretest scores 
7

Students' Teamwork Before and After IPE

Mishoe, Tufts, Diggs, Blando, Claiborne, Hoch, \& Walker
Journal of Research in Interprofessional Practice and Education

Vol. 8.1

2018
Table 3. Wilcoxon Signed Rank Test to compare pretest and posttest scores by student discipline, number of IPE experiences, and student level

\begin{tabular}{|c|c|c|c|c|c|}
\hline \multirow[t]{2}{*}{ Variable } & \multicolumn{2}{|c|}{ Teamwork total } & \multirow[t]{2}{*}{$Z^{*}$} & \multirow{2}{*}{$\begin{array}{c}\text { Asymp.sig. }{ }^{* *} \\
\text { (2-tailed) } p \text {-value }\end{array}$} & \multirow[t]{2}{*}{$R^{* * *}$} \\
\hline & $\begin{array}{l}\text { Negative } \\
\text { mean rank }\end{array}$ & $\begin{array}{c}\text { Positive } \\
\text { mean rank }\end{array}$ & & & \\
\hline $\begin{array}{l}\text { Student educational level } \\
\text { Undergraduate }(N=156) \\
\text { Graduate }(N=220)\end{array}$ & $\begin{array}{l}46.68 \\
43.75\end{array}$ & $\begin{array}{l}79.84 \\
56.43\end{array}$ & $\begin{array}{l}-6.6^{\mathrm{a}} \\
-3.7^{\mathrm{a}}\end{array}$ & $\begin{array}{l}<.001 \\
<.001\end{array}$ & $\begin{array}{l}.31 \\
.21\end{array}$ \\
\hline $\begin{array}{l}\text { Number of Prior IPE Experiences } \\
\text { None }(N=255) \\
1-2(N=103) \\
3-4(N=18)\end{array}$ & $\begin{array}{r}59.64 \\
27.43 \\
4.50\end{array}$ & $\begin{array}{r}96.90 \\
33.90 \\
6.56\end{array}$ & $\begin{array}{l}-7.0^{\mathrm{a}} \\
-2.4^{\mathrm{a}} \\
-1.7^{\mathrm{a}}\end{array}$ & $\begin{array}{r}<.001 \\
<.05 \\
.082\end{array}$ & $\begin{array}{r}.31 \\
.17 \\
-\end{array}$ \\
\hline $\begin{array}{l}\text { Student discipline } \\
\text { Physical therapy }(N=148) \\
\text { Dental hygiene }(N=117) \\
\text { Nursing }(N=80)\end{array}$ & $\begin{array}{l}41.59 \\
25.18 \\
18.80\end{array}$ & $\begin{array}{l}54.60 \\
40.00 \\
30.85\end{array}$ & $\begin{array}{l}-3.0^{\mathrm{a}} \\
-5.0^{\mathrm{a}} \\
-4.0^{\mathrm{a}}\end{array}$ & $\begin{array}{l}<.001 \\
<.001 \\
<.001\end{array}$ & $\begin{array}{l}.17 \\
.33 \\
.32\end{array}$ \\
\hline
\end{tabular}

Notes: ${ }^{\text {a }}$ based on negative ranks (pretest < posttest); $z$ is the number of standard deviations from the mean; ${ }^{* *}$ asymp. sig. is the asymptotic significance or $p$-value; ${ }^{* * *} r$ is the effect size

$(H(7)=38.22, p<.001)$ and also in the posttest scores $(H(7)=42.41, p<.001)$. On the pretest, post hoc analysis found that dental hygiene students had significantly higher scores (mean rank $=161.30$ ) than physical therapy students (mean rank $=110.63$, $U=5347.00, Z=-5.37, p<.001, r=.33$ ), and nursing students (mean rank $=140.13$, $U=3870, Z=-4.33, p<.001, r=.29)$ had significantly higher scores than physical therapy students (mean rank $=100.65$ ). All other comparisons were statistically non-significant. At posttest, post hoc analysis found that dental hygiene students also had significantly higher scores (mean rank $=142.06$ ) than physical therapy students' scores (mean rank $=96.79, U=4101.50, Z=-5.14, \mathrm{p}<.001, r=.34$ ). Additionally, nursing students' scores on the posttest were significantly higher (mean rank $=130.79$ ) than physical therapy students (mean rank $=84.37, p<.001, r=.39$ ). All other comparisons were statistically non-significant.

The Kruskal-Wallis tests also revealed differences in pretest scores $(\mathrm{H}(2)=18.58$, $p<.01)$ andposttest scores $(H(2)=15.20, p<.01)$ based on the number of prior IPE experiences. Post hoc analyses with Bonferroni correction confirmed that students with no prior IPE experience had significantly higher pretest scores (mean rank $=142.10$ ) than those with three to four IPE experiences (mean rank $=64.69$, $U=993.50, z=-4.0, \mathrm{p}<.001, r=.24)$. Students who had one to two prior IPE experiences had significantly higher pretest scores (mean rank $=65.07$ ) when compared to those with three to four prior IPE experiences (mean rank $=37.69, U=507.5, z=3.07$, $p=.002, r=.28)$. The other comparisons were statistically non-significant.

Students with no prior IPE experiences had significantly higher posttest scores (mean rank $=166.87$ ) than students with one to two IPE experiences (mean 
8

Students' Teamwork Before and After IPE

Mishoe, Tufts, Diggs, Blando, Claiborne, Hoch, \& Walker

Journal of Research in Interprofessional Practice and Education

Vol. 8.1

2018 rank $=138.21, U=8196.0, Z=-2.52, p=.01, r=.14)$ and students with no prior IPE experiences had significantly higher posttest scores (mean rank $=126.73$ ) than students with three to four IPE experiences $(p=.001, r=.21)$.

\section{Discussion}

This study reports on a single co-curricular event within a broader college-wide IPE process. It demonstrates that IPE co-curricular learning focused on roles and responsibilities can improve attitudes about teamwork and collaborative practice regardless of a student's program level, prior IPE experiences, or discipline. The findings are consistent with those reported in a comprehensive review of pre-licensure allied health curricula, suggesting that university-based IPE is feasible and effective [39]. Several studies have examined health professions students' acquisition of IPE knowledge and skills, although fewer studies have examined the extent to which IPE initiatives have changed the perceptions and values of health sciences students [40-42]. Studies have shown improvements in students' perceptions of one another's roles and responsibilities following IPE experiences, but not how learning about the roles and responsibilities of other health professionals can impact attitudes toward teamwork [43-44].

Nursing, dental hygiene, physical therapy, and other allied health students in this study had increased TRR scores for teamwork and collaboration following the IPE experience, regardless of whether they were undergraduate or graduate students or if they had less than two prior IPE experiences. These findings are similar to other case-based approaches, where interprofessional teams of students collaborated in decision-making and showed significant improvement in familiarity with the education and roles of each discipline, improvement in communication and teamwork skills, and improved team functioning $[45,46]$. These finding are important because studies suggest that baseline attitudes toward IPE have the strongest effect on attitudes toward IPE later in training [41] and can have lasting effects [47].

This study found that prior IPE learning affected students' attitudes toward teamwork. Students with no prior IPE experience or with one to two prior experiences had significantly higher pretest scores than those with three to four IPE experiences. On the posttest, students with no prior IPE experiences also had significantly higher scores when compared to students with one to two IPE experiences and to students with three to four IPE experiences. The study also found that students with no prior IPE learning had a significant increase in overall teamwork scores and on each of the nine TRR questions. Students who had one to two prior IPE learning experiences also showed significant increase in their teamwork and collaboration scores; however, not for every question. If students had more than two prior IPE experiences, there was no significant difference in their teamwork scores following the IPE learning experience. It is possible that a difference was not found because of the small sample size $(n=18)$ for this subset and the use of nonparametric statistics, which have insufficient power to identify a difference if one existed. However, others have reported that students who participated in interprofessional extracurricular activities, especially patient-based activities, reported more positive attitudes in the third 
9

Students' Teamwork Before and After IPE

Mishoe, Tufts, Diggs, Blando, Claiborne, Hoch, \& Walker

Journal of Research in Interprofessional Practice and Education

Vol. 8.1

2018 year than those who did not participate in such activities [41]. This suggests that students' attitudes toward teamwork could be affected by prior IPE learning and should be an important consideration when designing, implementing, and assessing co-curricular activities.

Although the results of this study show significant gains in TRR scores for all health sciences students, there were also some educational-level and disciplinary differences. Undergraduate students scored significantly higher on both the pretest and posttest compared to the graduate students. These findings are consistent with studies suggesting that health profession students differ in their attitudes toward IPE based on discipline. This is also one of the first studies to include athletic training, cytotechnology, dental hygiene, environmental health, and nuclear medicine technology students $[39,48,49]$. Other studies have reported on the limited involvement of dental hygienists in IPE and IPCP and the recognition that oral health professionals can be meaningful collaborators in interprofessional public health services [50]. Some studies have reported that characteristics associated with having a more positive attitude about IPE at various points in time include being a nursing student, being female, and having more health experiences [39,41,51,52]. Perceived differences in power and a poor IPE participation rate among some health professions have also been reported [52-55]. These findings indicate that nursing and dental hygiene students had more positive attitudes about teamwork before and after the intervention. Although physical therapy students in this study had a significant increase in their teamwork and collaboration scores following the IPE experience, the effect size was small, and further analysis show that their pretest scores and posttest scores were significantly lower than dental hygiene, nursing, and the other health sciences students' scores. This finding is consistent with other studies, which have shown that physical therapy and medical students have lower scores on measures of teamwork and collaboration and value IPE and patient-centered learning less than other health professions and nursing students [41-43,52,53]. However, studies are increasingly showing positive faculty and student attitudes toward IPE for these disciplines, and also that physicians, physical therapists, and others with advanced or graduate degrees can have improved and lasting perceptions of teamwork [56-60].

Nonetheless, there are many challenges to incorporating IPE into educational programs, such as schedule coordination, faculty development, curricula overload, resources, space, faculty engagement, clinical partnerships, and administrative support [49,57,61-63]. This study demonstrates that co-curricular learning can address some of these barriers and facilitate students' IPE competencies. Other major challenges in the adoption of IPE and IPCP is the tendency to uphold traditional professional boundaries rather than create and implement new team-based roles [52,63-66]. This study demonstrates how a team-based approach can overcome traditional educational boundaries to provide students with IPE activities that can significantly increase their teamwork scores.

It is important that students' curricula, including clinical experiences, reinforce students' IPE competencies gained in an educational experience as described in this 
10

Students' Teamwork Before and After IPE

Mishoe, Tufts, Diggs, Blando, Claiborne, Hoch, \& Walker

Journal of Research in Interprofessional Practice and Education

Vol. 8.1

2018 study. However, there are also many barriers to teamwork and collaborative practice, including preconceived stereotypes, relationships of power, and differing professional cultures, which includes values, beliefs, attitudes, customs, language/jargon, and behaviours $[31,32,54,67]$. Health professionals enter their careers with specific expertise in their own discipline and often lack a common understanding of the issues, values, and problem-solving approaches necessary to function effectively as a team member. In addition to skill acquisition, it is important that IPE experiences positively impact attitudes toward teamwork and collaborative practice, as demonstrated in this study. For collaborative practice, team members must understand others' roles and responsibilities and assume joint responsibilities with patients and their families to achieve desired patient outcomes. Professional education programs need to facilitate interprofessional socialization (IPS) to prepare health professionals for effective team-based care; however, IPS frameworks are limited [68,69]. Collaboration between educational programs and healthcare providers are also necessary to create the types of authentic learning experiences needed to advance IPE and IPCP.

This study is limited by smaller sample sizes for some disciplines, data collection at one institution only, and the lack of a control group. This limits its generalizability for the development of the best IPE strategies to positively impact teamwork in practice. This study suggests that an improved understanding of the roles and responsibilities of others can potentially explain the improvement in attitudes toward teamwork after training. Given the absence of a control group, this is only a tentative explanation that will require further investigation. Future research requires the longterm evaluation of interprofessional education and practice using quantitative and qualitative methods, with adequate funding for implementation, faculty committed to professional development, and researchers conducting more longitudinal followups of learner and patient outcomes.

This study demonstrates that providing opportunities for pre-licensure students to understand the roles of other disciplines through interactive, co-curricular, casebased learning can enhance the positive attitudes toward teamwork that are important for interprofessional practice [7]. Students came together and began to foster positive relationships not based on professional rivalry, stereotypes, or power, but on mutual understanding and respect. Although this study demonstrates that a cocurricular IPE learning method generates positive results similar to those previously reported, it cannot be assumed that changes in attitudes will result in changes in behaviour that lead to effective teamwork and improved patient outcomes [70]. Additional research is needed to determine the lasting effects of positive changes in teamwork attitudes and whether attitudinal changes create actual behavioural changes and role changes as well as improvements in healthcare outcomes. This area is ripe with opportunities for health services researchers [66,67,71]. A recent study found that when the contextual variables of IPCP were controlled by taking healthcare professionals out of their normal work environments, few of the traditional, stereotypical behavioural differences that have been attributed to the professional groups were observed [72]. These findings are promising and suggest that 
11

Students' Teamwork Before and After IPE

Mishoe, Tufts, Diggs, Blando, Claiborne, Hoch, \& Walker
Journal of Research in Interprofessional Practice and Education

Vol. 8.1

2018 contextual variables can remove barriers for IPE and IPCP. Perhaps future research on IPCP should focus less on skills and attitudes of health professionals and more on organizational and contextual variables that create or remove barriers. Furthermore, health professionals could benefit from IPE experiences that focus specifically on teamwork interventions, and theoretical models of teamwork to not only advance IPE research, but also contribute to improving healthcare outcomes $[69,73-75]$.

\section{Acknowledgements}

The authors would like to thank the Dean's Office in the College of Health Sciences for internally funding this study.

\section{Abbreviations}

College of Health Sciences (COHS)

Interprofessional collaborative practice (IPCP)

Interprofessional Attitudes Scale (IPAS)

Interprofessional education (IPE)

Interprofessional Education Collaborative (IPEC)

Statistical Package for the Social Sciences (SPSS)

Teamwork, Roles, and Responsibilities subscale (TRR)

\section{References}

1. Institute of Medicine. (1972). Educating for the heath team. Washington, DC: National Academy of Sciences.

2. Institute of Medicine. (2000). To err is human: Building a safer health system. Washington, DC: National Academy Press.

3. Institute of Medicine. (2001). Crossing the quality chasm. Washington, DC: National Academy Press.

4. Institute of Medicine. (2013). Interprofessional education for collaboration: Learning how to improve health from interprofessional models across the continuum of education to practice: Workshop summary. Washington, DC: The National Academies Press.

5. Institute of Medicine. (2015). Measuring the impact of interprofessional education on collaborative practice and patient outcomes. Washington, DC: The National Academies Press.

6. Barr, H., Helme, M., \& D’Avray, L. (2013). Interprofessional Education in the United Kingdom (1997-2013). Fareham, UK: CAIPE. http://www.tandfonline.com/doi/abs/10.3109/13561820 .2014 .981479

7. Cook, D.A. (2005). Models of interprofessional learning in Canada. Journal of Interprofessional Care, 19(supplement 1), 107-115.

8. Canadian Interprofessional Health Collaborative. (2010). A national interprofessional competency framework. Vancouver, BC: CIHC. URL: www.cihc.ca [June 9, 2017].

9. Flood, B., McKinstry, W., Friary, P., \& Purdy, S. (2014). Cultivating interprofessional practice in New Zealand: An inter-sectorial approach to developing interprofessional education. Journal of Allied Health, 43(3), e59-64.

10. Reeves, S., Goldman, J., Gilbert, J., Tepper, J., Silver, I., Suter, E., \& Zwarenstein, M.(2011). A scoping review to improve conceptual clarity of interprofessional interventions. Journal of Interprofessional Care, 25, 167-174.

11. World Health Organization. (2010). Framework for action on interprofessional education \& collaborative practice (1st ed.). Geneva, CH: Department of Human Resources for Health, World Health Organization. URL: http://www.who.int/hrh/resources/framework_action/en/ [April 13, 2017].

12. Schmitt, M.H. (2001). Collaboration improves quality of care: Methodological challenges and evidence from US health care research. Journal of Interprofessional Care, 15, 47-66. 
Students' Teamwork Before and After IPE

Mishoe, Tufts, Diggs, Blando, Claiborne, Hoch, \& Walker

Journal of Research in Interprofessional Practice and Education

Vol. 8.1

2018
13. Reeves, S., Perrier, L., Goldman, J., Freeth, D., \& Zwarenstein, M. (2013) Interprofessional education: Effects on professional practice and healthcare outcomes (update). The Cochrane Database of Systematic Reviews: CD002213. doi: 10.1002/14651858.CD002213.pub3

14. Lozano, P., Finkelstein, J.A., Carey, V.J., Wagner, E.H., Inui, T.S., Fuhlbrigge, A.L., Soumerai, S.B., Sullivan, S.D., Weiss, S.T., \& Weiss, K.B. (2004). A multisite randomized trial of the effects of physician education and organizational change in chronic-asthma care: Health outcomes of the pediatric asthma care patient outcomes research team II study [electronic version]. Archives of Pediatrics and Adolescent Medicine, 158(9), 875-883. doi: 10.1001/archpedi.158.9.875

15. Firth-Cozens, J. (2001). Cultures for improving patient safety through learning: The role of teamwork. Quality in Health Care, 10(supplement II), ii26-ii31.

16. Gjessing, K., Torgé, C.J., Hammar, M., Dahlberg, J., \& Faresjö, T. (2014). Improvement of quality and safety in health care as a new interprofessional learning module-Evaluation from students. Journal of Multidisciplinary Health, 7, 341-347. https://doi.org/10.2147/JMDH.S62619

17. Welp, A., \& Manser, T. (2016). Integrating teamwork, clinician occupational well-being and patient safety - development of a conceptual framework based on a systematic review. BMC Health Services Research, 16(1). https://doi.org/10.1186/s12913-016-1535-y

18. Morey, J.C., Simon, R., Jay, G.D., Wears, R.L., Salisbury, M., Dukes, K.A., \& Berns, S.D. (2002). Error reduction and performance improvement in the emergency department through formal teamwork training: Evaluation results of the MedTeams project. Health Services Research, 37(6), 1553-1581. URL: http://proxy.lib.odu.edu/login?url=http://search.proquest.com.proxy .lib.odu.edu/docview/72832035?accountid=12967 [June 15, 2017].

19. Nageswaran, S., Donoghue, N., Mitchell, A., \& Givner, L.B. (2017). An innovative collaborative model of care for undiagnosed complex medical conditions. Pediatrics, 139(5), e20163373. URL: http://pediatrics.aappublications.org/content/pediatrics/139/5/e20163373.full.pdf [July $17,2017]$.

20. Malt, G. (2015). Cochrane Review Brief: Brief: Interprofessional Education: Effects on professional practice and healthcare outcomes. Online Journal of Issues in Nursing, 20(2), 12. URL: http://www.nursingworld.org/MainMenuCategories/ANAMarketplace/ANAPeriodicals/OJIN /Columns/Cochrane-Review-Briefs/Interprofessional-Education.html [June 14, 2017].

21. Laurent, M.G., Hermes, R.P., Braspenning, J.C., Sibbald, B., \& Grol, R.P. (2004). Impact of nurse practitioners on workload of general practitioners: Randomized controlled trial. [electronic version]. British Medical Journal, 328(7445), 927. doi: 10.1136/bmj.38041.493519.EE

22. Øvretveit, J.C., Shekelle, P.G., Dy, S.M., Mcdonald, K.M., Hempel, S., Pronovost, P., \& Wachter, R.M. (2011). How does context affect interventions to improve patient safety? An assessment of evidence from studies of five patient safety practices and proposals for research. British Medical Journal of Quality \& Safety, 20(7), 604. https://doi.org/10.1136/bmjqs.2010.047035

23. Sommers, L.S., Marton, K.I., Barbaccia, J.C., \& Randolph, J. (2000). Physician, nurse, and social worker collaboration in primary care for chronically ill seniors. Archives of Internal Medicine, 160(12), 1825-1833.

24. Hardin, L., Kilian, A., \& Spykerman, K. (2017) Competing health care systems and complex patients: An inter-professional collaboration to improve outcomes and reduce health care costs. Journal of Interprofessional Education \& Practice, 7, e5-10. URL: https://www-clinicalkey-com .proxy.lib.odu.edu/service/content/pdf/watermarked/1-s2.0-S2405452616301033.pdf?locale =en_US [June 8, 2017].

25. Chang, W.Y., Ma, J.C., Chiu, H.T., Lin, K.C., \& Lee, P.H. (2009). Job satisfaction and perceptions of quality of patient care, collaboration and teamwork in acute care hospitals. Journal of Advanced Nursing, 65(9), 1946-1955.

26. Gausvik, C., Lautar, A. Miller L, Pallerla, H., \& Schlaudecke, J. (2015). Structured nursing communication on interdisciplinary acute care teams. Journal of Multidisciplinary Health Care, 2015(8), 33-37. URL: https://www.dovepress.com/structured-nursing-communication-on -interdisciplinary-acute-care-teams-peer-reviewed-fulltext-article-JMDH [May 12, 2017].

27. Buttigieg, S.C., West, M.A., \& Dawson, J.F. (2011). Well structured teams and the buffering of hospital employees from stress. Health Services Management Research, 24(4), 203-212.

28. Abualrub, R.F., Gharaibeh, H.F., \& Bashayreh, A.E.I. (2012). The relationships between safety climate, teamwork, and intent to stay at work among Jordanian hospital nurses. Nursing Forum, 47(1), 65-75.

29. West, M.A., \& Lyubovnikova, J. (2013). Illusions of team working in health care. Journal of Organization and Management, 27(1), 134-142.

30. Ritter, D. (2011). The relationship between healthy work environments and retention of nurses in a hospital setting. Journal of Nursing Management, 19(1), 27-32. 
Students' Teamwork Before and After IPE

Mishoe, Tufts, Diggs, Blando, Claiborne, Hoch, \& Walker

Journal of Research in Interprofessional Practice and Education

Vol. 8.1

2018
31. Blue, A.V., Zoller, J., Stratton, T.D., Elam, C.L., \& Gilbert, J. (2010). Interprofessional education in US medical schools. Journal of Interprofessional Care, 24, 204-206.

32. Hall, P. (2005). Interprofessional teamwork: Professional attitudes as barriers. Journal of Interprofessional Care, 19(supplement 1), 188-196. doi: 10.1080/13561820500081745

33. Kirsch, D., \& Ast, C. (2015) Interprofessionalism: Educating to meet patient needs. Anatomical Sciences Education, 8, 296-298. http://onlinelibrary.wiley.com.proxy.lib.odu.edu/doi/10.1002 /ase.1504/abstract

34. Moreo, K., Greene, L., \& Sapir, T. (2016). Improving interprofessional and coproductive outcomes of care for patients with chronic obstructive pulmonary disease. British Medical Journal Quality Improvement Reports, 5(1). https://doi.org/10.1136/bmjquality.u210329.w4679

35. Interprofessional Education Collaborative. (2011). Expert Panel Core Competencies for Interprofessional Collaborative Practice: Report of an Expert Panel Interprofessional Education Collaborative. Washington, DC: Interprofessional Education Collaborative. URL: http://www .aacn.nche.edu/education-resources/ipecreport.pdf [June 6, 2017].

36. Brashers, V., Owen, J., \& Haislip, J. (2015). Interprofessional Education and Practice Guide No. 2: Developing and implementing a center for interprofessional education. Journal of Interprofessional Care, 29(2), 95-99. doi: 10.3109/13561820.2014.962130 [December 19, 2017].

37. Englander, R., Cameron, T., Ballard, A.J., Dodge, J., Bull, J., \& Aschenbrener, C.A. (2013). Toward a common taxonomy of competency domains for the health professions and competencies for physicians. Academic Medicine, 88, 1088-1094.

38. Oandasan, I., \& Reeves, S. (2005). Key elements of interprofessional education. Part 2: Factors, processes and outcomes. Journal of Interprofessional Care, 19(supplement 1), 39-48.

39. Norris, J., Carpenter, M.J.G., Eaton, M.J., Guo, J.W., Lassche, M.M., Pett, M.A., \& Blumenthal, D.K. (2015). Development and construct validation of the Interprofessional Attitudes Scale. Academic Medicine: Journal of the Association of American Medical Colleges, 90(10), 1394-1400.

40. Olson, R., \& Bialocerkowski, A. (2014). Interprofessional education in allied health: A systematic review. Medical Education, 48(3), 10.

41. Kashner, T.M., Hettler, D.L., Zeiss, R.A., Aron, D.C., Bernett, D.S., Byrne, J.M., Cannon, G.W., Chang, B.K., Dougherty, M.B., Gilman, S.C., Hollan, G.J., Kaminetzky, C.P., Wicker, A.B., \& Keitz, S.A. (2017). Has interprofessional education changed learning preferences? A national perspective. HSR: Health Services Research, 52(1), 268-290.

42. Wong, R.L., Fahs, D.B., Talwalkar, J.S., Colson, E.R., Desai, M.M., Kayingo, G., Balanda, M., Luczak, A.G., \& Rosenthal, M.S. (2016). A longitudinal study of health professional students' attitudes towards interprofessional education at an American University. Journal of Interprofessional Care, 30(2), 9.

43. Kenaszchuk, C., Rykhoff, M., Collins, L., McPhail, S., \& van Soeren, M. (2012). Positive and null effects of interprofessional education on attitudes toward interprofessional learning and collaboration. Advances in Health Sciences Education, 17(5), 651-669.

44. Jacomino, M., Bamdas, J.A.M., Keller, K., Hamlin, E., Hawkins, M., Gordon, S., \& Ouslander, J.G. (2015). An innovative interprofessional education program for university medical, nursing, and social work students learning in teams during sessions and visits with geriatric mentors. Journal of Interprofessional Education \& Practice, 1(3-4), 100-103. https://doi.org /10.1016/j.xjep.2015.10.003

45. Tartavoulle, T.M., English, R., Gunaldo, T.P., Garbee, D., Mercante, D.E., Andrieu, S.C., \& Johnson, J.L. (2016). Using the IDEA framework in an interprofessional didactic elective course to facilitate positive changes in the roles and responsibility competency. Journal of Interprofessional Education \& Practice, 2, 21-24. https://doi.org/10.1016/j.xjep.2016.03.003

46. Sweet, B.V., Madeo, A., Fitzgerald, M., House, J.B. Pardee, M., Zebrack, B., Sweier, D., Hornyak, J. Arslanian-Engoren, C., Mattison, D., Dubin, L., Stojan, J., \& Mueller, B.A. (2017). Moving from individual roles to functional teams: A semester-long course in case-based decision making. Journal of Interprofessional Education \& Practice, 7, 11-16. https://dx.doi.org/10.1016/j.xjep .2017.01.003

47. Wellmon, R., Gilin, B., Knauss, L., \& Linn, M.I. (2012). Changes in student attitudes toward interprofessional learning and collaboration arising from a case-based educational experience. Journal of Allied Health, 41(1), 26-34. URL: http://proxy.lib.odu.edu/login?url=http://search .proquest.com.login.proxy.lib.odu.edu/docview/1347609331 ?accountid=12967 [June 9, 2017].

48. Sytsma, T., Haller, E., Youdas, J., Krause, D., Hellyer, N., Pawlina, W., \& Lachman, N. (2015). Long-term effect of a short interprofessional education interaction between medical and physical therapy students. Anatomical Sciences Education, 8, 7. https://doi.org/10.1002/ase.154 
Students' Teamwork Before and After IPE

Mishoe, Tufts, Diggs, Blando, Claiborne, Hoch, \& Walker

Journal of Research in Interprofessional Practice and Education

Vol. 8.1

2018
49. Breitbach, A.P., \& Richardson, R. (2015). Interprofessional education and practice in athletic training. Athletic Training Education Journal, 10(2), 170-182.

50. Furgeson, D., Kinney, J.S., Gwozdek, A.E., Wilder, R., \& Inglehart, M. (2015). Interprofessional education in U.S. dental hygiene programs: A national survey. Journal of Dental Education, 79(11), 1286-1294.

51. Kanji, Z., Lin, D., \& Krekoski, C. (2017). Interprofessional education and collaborative practice. Canadian Journal of Dental Hygiene, 51(1), 42-48. URL: http://search.proquest.com.proxy .lib.odu.edu/docview/1869039261/citation/505775EE5A584A5CPQ/1 [May 12, 2017].

52. Curran, V.R., Sharpe, D., Flynn, K., \& Button, P. (2010). A longitudinal study of the effect of an interprofessional education curriculum on student satisfaction and attitudes towards interprofessional teamwork and education. Journal of Interprofessional Care, 24(1), 41-52. doi:10.3109 /13561820903011927

53. Cameron, A., Rennie, S., DiProspero, L., Langlois, S., Wagner, S., Potvin, M., Dematteo, D., LeBlanc, V., \& Reeves, S. (2009). An introduction to teamwork: Findings from an evaluation of an interprofessional education experience for 1,000 first-year health science students. Journal of Allied Health, 38(4), 220-226.

54. Davies, K., Harrison, K., Clouder, D.L., Gilchrist, M., McFarland, L., \& Earland, J. (2011). Making the transition from physiotherapy student to interprofessional team member. Physiotherapy, 97, 139-44.

55. Baker, L., Egan-Lee, E., Martimianakis, M.A., \& Reeves, S. (2011). Relationships of power: Implications for interprofessional education. Journal of Interprofessional Care, 25(2), 98-104. https: //doi.org/10.3109/13561820.2010.505350

56. Buckley, S., Hensman, M., Thomas, S., Dudley, R., Nevin, G., \& Coleman, J. (2012). Developing interprofessional simulation in the undergraduate setting: Experience with five different professional groups. Journal of Interprofessional Care, 26, 362-369.

57. Dumke, E.K., VanderWielen, L., Harris, K.A., \& Ford-Smith, C.D. (2016). Interprofessional education in an enrichment programme for prospective health sciences students. Journal of Interprofessional Care, 30(2), 245-247. https://doi.org/10.3109/13561820.2015.1089224

58. Talwalkar, J.S., Fahs, D.B., Kayingo, G., Wong, R., Jeon, S., \& Honan, L. (2016). Readiness for interprofessional learning among healthcare professional students. International Journal of Medical Education, 7, 144-148. URL: https://doi.org/10.5116/ijme.570d.7bd8

59. Wise, H.H., Frost, J.S., Resnik, C., Davis B. P., \& Iglarsh, Z.A. (2015). Interprofessional educational exploration in physical therapist education. Journal of Physical Therapy Education, 29(2), 72-83.

60. Eckmeki, O. (2013). Promoting collaboration in health care teams through interprofessional education: A simulation case study. International Journal of Higher Education, 2(1), 6.

61. Casimiro, L., Hall, P., Kuziemsky, C., O’Connor, M., \& Varpio, L. (2015). Enhancing patientengaged teamwork in healthcare: An observational case study. Journal of Interprofessional Care, 29(1), 6.

62. Ravet, J. (2012). From interprofessional education to interprofessional practice: Exploring the implementation gap. Professional Development in Education, 38(1), 49-64. http://dx.doi.org/10 $.1080 / 19415257.2011 .576263$

63. Shoemaker, M., Beasley, J., Cooper, M., Perkins, R., \& Smith, J. (2011). A method for providing high-volume interprofessional simulation encounters in physical and occupational therapy education programs. Journal of Allied Health, 40(1), e15-21.

64. Loversidge, D., \& Demb, A. (2015). Faculty perceptions of key factors in interprofessional education. Journal of Interprofessional Care, 29(4), 298-304. doi: 10.3109/13561820.2014.991912

65. Beales, J., Walji, R., Papoushek, C., \& Austin, Z. (2011). Exploring professional culture in the context of family health team interprofessional collaboration. URL: http://commons.pacificu.edu /cgi/viewcontent.cgi?article=1012\&amp;context=hip [June 14, 2017].

66. Leipzig, R.M., Hyer, K., Kirsten, E., Wallenstein, S., Vezina, M.L., Fairchild, S., Cassel, C.K., \& Howe, J.L. (2002). Attitudes toward working on interdisciplinary teams: A comparison by discipline. Journal of the American Geriatric Society, 50, 1141-1148.

67. Adams Tufts, K. (2016). A “CLARION" call for embracing IPE as the status quo for preparing health professionals to engage in interprofessional health research. American Journal of Health Research, 4(2-1), 1-3. doi: 10.11648/j.ajhr.s.2016040201.11

68. Thistlethwaite, J.E. (2012). Interprofessional education: A review of context, learning and the research agenda. Medical Education, 46, 12. https://doi.org/10.1111/j.1365-2923.2011.04143.x

69. Khalili, H., Orhard, C., Laschinger, H., \& Farah, R. (2013). An interprofessional education socialization framework for developing an interprofessional identity among health professions students. Journal of Interprofessional Care, 27(6), 5. 
Students' Teamwork Before and After IPE

Mishoe, Tufts, Diggs, Blando, Claiborne, Hoch, \& Walker
70. D’Angelo, M.R., Saperstein, A.K., Seibert, D.C., Durning, S.J., Varpio, L., \& D’Angelo, M. R. (2016). Military interprofessional health care teams: How USU is working to harness the power of collaboration. Military Medicine, 181(11), 1404-1406. https://doi.org/10.7205/MILMED-D15-00558

71. Foy, R., Ovretveit, J., Shekelle, P.G., Pronovost, P.J., Taylor, S.L., Dy, S., \& Wachter, R.M. (2011). The role of theory in research to develop and evaluate the implementation of patient safety practices. British Medical Journal Quality \& Safety, 20(5), 453-459. URL: http://qualitysafety .bmj.com/content/20/5/453.short [June 9, 2017].

72. Lawn, S. (2016). Moving the interprofessional education research agenda beyond the limits of evaluating student satisfaction. Journal of Research in Interprofessional Practice and Education, 6(2). URL: http://www.jripe.org/index.php/journal/article/view/239 [June 14, 2017].

73. Braithwaite, J., Clay-Williams, R., Vecellio, E., Marks, D., Hooper, T., Westbrook, M., \& Ludlow, K. (2016). The basis of clinical tribalism, hierarchy and stereotyping: a laboratory-controlled teamwork experiment. British Medical Journal Open, 6(7). https://doi.org/10.1136/bmjopen -2016-012467

74. Bridges, D., Davidson, R., Odegard, P., Maki, I., \& Tomkowiak, J. (2011). Interprofessional collaboration: Three best practice models of interprofessional education. Medical Education Online, 16. https://doi.org/10.3402/meo.v16i0.6035

75. Chakraborti, C., Boonyasai, R.T., Wright, S.M., \& Kern, D.E. (2008). A systematic review of teamwork training interventions in medical student and resident education. Journal of General Internal Medicine, 23(6), 846-853. https://doi.org/10.1007/s11606-008-0600-6

76. McEwan, D., Ruissen, G.R., Eys, M.A., Zumbo, B.D., \& Beauchamp, M.R. (2017). The effectiveness of teamwork training on teamwork behaviors and team performance: A systematic review and meta-analysis of controlled interventions. PloS One, 12(1), e0169604. URL: http://journals .plos.org/plosone/article?id=10.1371/journal.pone.0169604 [June 14, 2017]. 
16

Students' Teamwork

Before and After IPE

Mishoe, Tufts, Diggs, Blando Claiborne, Hoch, \& Walker

\section{Appendix A}

\section{COHS Interprofessional Education Case Study \#1, Roles and Responsibilities}

Mrs. Althea Gibson has received a diagnosis of bladder cancer. Mrs. Gibson is 45 years old, is married, and has 3 children; 2 who are still at home. She was a college athlete and is still a "weekend warrior" who participates in marathons. She trains for marathons 5 days a week, does resistance training on 2 days, and loves Zumba. It is believed that her relative risk for developing bladder cancer may have been occupational because she has worked in the textile industry for 20 years and was exposed to aniline dyes.

She was admitted to Monarch General for chemotherapy treatment. Potential chemotherapy side effects include generalized gingival inflammation and xerostomia (dry mouth). It is expected that she may also become quite debilitated as a result of the planned chemo and radiation therapy. Therefore, she will need extensive physical rehabilitation. She has been referred to a rehabilitation service that specializes in both physical therapy and athletic training.

The purpose of today's College of Health Sciences Interprofessional Education learning activity is to enhance your knowledge of IPEC Competency \#2, Roles and Responsibilities: using the knowledge of one's own role and those of other professions to appropriately assess and address the healthcare needs of the patients and populations served. An understanding of roles and responsibilities is an important first step to working in interprofessional groups and ultimately to building wellfunctioning interprofessional teams and engage in effective teamwork (IPEC Competency \#4, Teams and Teamwork). 